\title{
Valuing informal carers' quality of life using best-worst scaling-Finnish preference weights for the Adult Social Care Outcomes Toolkit for carers (ASCOT-Carer)
}

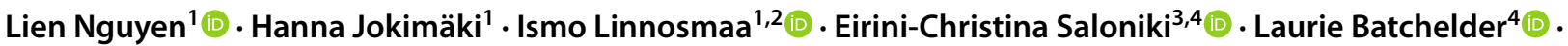

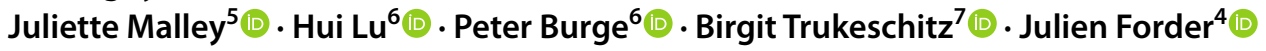

Received: 3 July 2020 / Accepted: 13 July 2021 / Published online: 1 September 2021

(c) The Author(s) 2021

\begin{abstract}
This study developed Finnish preference weights for the seven-attribute Adult Social Care Outcomes Toolkit for carers (ASCOT-Carer) and investigated survey fatigue and learning in best-worst scaling (BWS) experiments. An online survey that included a BWS experiment using the ASCOT-Carer was completed by a sample from the general population in Finland. A block of eight BWS profiles describing different states from the ASCOT-Carer were randomly assigned to each respondent, who consecutively made four choices (best, worst, second best and second worst) per profile. The analysis panel data had 32,160 choices made by 1005 respondents. A scale multinomial logit (S-MNL) model was used to estimate preference weights for 28 ASCOT-Carer attribute levels. Fatigue and learning effects were examined as scale heterogeneity. Several specifications of the generalised MNL model were employed to ensure the stability of the preference estimates. The most and least-valued states were the top and bottom levels of the control over daily life attribute. The preference weights were not on a cardinal scale. We observed the position effect of the attributes on preferences associated with the best or secondbest choices. A learning effect was found. The established preference weights can be used in evaluations of the effects of long-term care services and interventions on the quality of life of service users and caregivers. The learning effect implies a need to develop study designs that ensure equal consideration to all profiles (choice tasks) in a sequential choice experiment.
\end{abstract}

Keywords Adult Social Care Outcomes Toolkit for carers (ASCOT-Carer) - Informal care - Outcome measurement . Quality of life $\cdot$ Evaluation $\cdot$ Best-worst scaling (BWS) $\cdot$ Scale multinomial logit $\cdot$ Learning and fatigue effects

JEL Classification C35 $\cdot \mathrm{C} 90 \cdot \mathrm{I} 18 \cdot \mathrm{I} 31 \cdot \mathrm{I} 39$

\section{Lien Nguyen}

lien.nguyen@thl.fi

1 Finnish Institute for Health and Welfare (THL), Helsinki, Finland

2 Department of Health and Social Management, University of Eastern Finland, Kuopio, Finland

3 Centre for Health Services Studies (CHSS), University of Kent, Kent, UK

4 Personal Social Services Research Unit (PSSRU), University of Kent, Kent, UK

5 Care Policy and Evaluation Centre, London School of Economics and Political Science, London, UK

6 RAND Europe, Cambridge, UK

7 Research Institute for Economics of Aging, WU Vienna University of Economics and Business, Vienna, Austria

\section{Introduction}

The provision of long-term care (LTC) for older people in various OECD countries has been substantially contributed to by informal carers [1]. The projected growth in the LTC needs in Europe has imposed a difficult question of how to effectively allocate limited resources within LTC systems to support people with LTC needs and their informal carers $[2,3]$. Concerning the supply side of informal care, providing care can lead to unfavourable effects on carers' health, well-being, life satisfaction and overall quality of life (QoL). High-intensity caregiving is found to be associated with worse mental health, increased emotional and physical strain, and loneliness or feelings of isolation [4-7]. It is also associated with decreased life satisfaction [8] and increased use of drugs and outpatient care [9]. 
Systematic reviews $[10,11]$ indicate that informal carers' well-being, stress or burden, mental health, needs and experience have been measured by a number of measures, such as the Caregiver Burden Interview [12], the CES Depression Scale [13] and the Social Satisfaction Scale [14]. Since these measures focus on specific aspects of carers' well-being, they may omit outcomes or experiences that are important to carers. The use of appropriate measures and methods to assess the costs and outcomes related to the provision of informal care and the QoL of carers has become particularly important in effectiveness and cost-effectiveness studies that include informal care [15].

Adult social care aims to promote the well-being and QoL of adults needing support with daily activities and their informal carers (caregivers). The Adult Social Care Outcomes Toolkit for service users (ASCOT) was developed to measure adult care recipients' social care-related quality of life (SCRQoL) and the effectiveness of support and services [16]. As carers' outcomes and experiences differ from those of services users, the Adult Social Care Outcomes Toolkit for carers (ASCOT-Carer) was also developed [17, 18], and English preference weights for the original measure were recently derived [19]. The ASCOT-Carer can be used in effectiveness and cost-effectiveness evaluations of interventions focusing on social care and support to caregivers [18].

Similar to numerous generic preference-based measures [20], the English ASCOT-Carer preference weights [19] capture the values of the general population for ASCOT-QoL states in England. This reflects the point of view that the values of the general population should be used in decisions about how to allocate the limited resources in the health and social care sector as the general population pays for services and the provision of services is tax-funded in many European countries [21]. Furthermore, comparative studies have indicated that the general population's preferences differ between countries according to culture and health and social care delivery systems [20, 22, 23]. Therefore, we should be cautious about valuing QoL states in one country using preference weights for QoL states that were developed in the context of another country [22, 23]. In the field of health-related QoL measurement, the usual practice is to develop country-specific preference weights to better explain the country's own populations' perceptions and values regarding various health states [24-26]. This approach was taken for translated-versions of ASCOT [27-29] (in German, Japanese and Finnish) and ASCOT-Carer [30] (in German) measures.

To apply the ASCOT-Carer measure in Finland, we translated the measure from English to Finnish in 2015-2016, following international guidelines in the translation process
[31]. ${ }^{1}$ Since the preference weights for the Finnish-translated measure has not been developed yet, the primary aim of this study was to estimate Finnish preference weights for the Finnish ASCOT-Carer measure. Following Netten et al. [16], we collected choice data from a web-based general population survey that included a best-worst scaling (BWS) experiment $[32,33]$. Using the BWS data and multinomial logit models, we estimated the preference weights for attribute levels of the Finnish ASCOT-Carer.

The recent literature on choice experiments has indicated that sequential choice tasks can give rise to learning or fatigue [34-36], where respondent choices become more consistent (learning) or less consistent (fatigue) over the course of the experiment. In the BWS experiment, each respondent had eight sequential choice tasks and made four consecutive choices per task. Since these repeated tasks created a prerequisite to explore fatigue and learning during the choice experiment, an auxiliary aim of the study was to investigate the effect of learning and fatigue on respondent choices and preference estimates in the BWS experiment. This study contributes to enlarging the number of valid measures for use to evaluate capability-based QoL in a general population [37] and better understanding the effect of fatigue and learning on respondent choices in BWS experimental studies.

\section{Methods}

\section{ASCOT-Carer, best-worst scaling (BWS) and BWS tasks}

The ASCOT-Carer measure has seven four-level attributes concerning different aspects of informal carers' SCRQoL: (1) occupation; (2) control over daily life [control]; (3) looking after yourself [self-care]; (4) personal safety [safety]; (5) social participation and involvement [participation]; (6) space and time to be yourself [space-and-time]; and (7) feeling supported and encouraged [support] (Table 1). The attribute levels measure carers' need intensity: Level_1 (top level) indicates the most favourable situation-the 'ideal state' - and level_4 (bottom level) indicates the least favourable situation, i.e. 'high needs', whereas level_2 and level_3 indicate in-between situations (i.e. 'no needs' and 'some needs', respectively).

Following the approach used in Netten et al. [16], we used the BWS method to collect data to derive Finnish preference weights for the Finnish version of the ASCOT-Carer

\footnotetext{
1 Both four-level self-completion (SCT4) and interview (INT4) questionnaires for both the ASCOT and ASCOT-Carer were translated into Finnish (www.pssru.ac.uk/ascot/translations).
} 
Table 1 ASCOT-Carer attributes describing informal carers' social care-related quality of life

\begin{tabular}{ll}
\hline Attribute & Definition \\
\hline Occupation & $\begin{array}{c}\text { Being sufficiently occupied in a range of meaningful, enjoyable activities, whether it be formal employment, } \\
\text { unpaid work, caring for others or leisure activities } \\
\text { Choosing what to do and when to do it and having control over one's daily life and activities } \\
\text { Control over daily life } \\
\text { Looking after yourself }\end{array}$ \\
$\begin{array}{l}\text { Feeling able to look after oneself in terms of eating well and getting enough sleep } \\
\text { Feeling safe and secure, where concerns about safety can include fear of abuse or other physical harm or } \\
\text { accidents that may arise as a result of caring }\end{array}$ \\
$\begin{array}{l}\text { Being content with their social situation, where the social situation includes sustenance of meaningful rela- } \\
\text { tionships with friends and family, as well as feeling involved and part of their community }\end{array}$ \\
Having space and time in everyday life. Enough time away from caring to have a life of their own outside of \\
the caring role
\end{tabular}

Source. Rand et al. [18]

(i) First choice from seven options [best]

\begin{tabular}{|l|}
\hline I don't do anything I value or enjoy with my time \\
\hline I have as much control over my daily life as I want \\
\hline Sometimes I can't look after myself well enough \\
\hline I feel less than adequately safe \\
\hline I have adequate social contact with people \\
\hline I have all the space and time I need to be myself \\
\hline I feel I have no encouragement and support \\
\hline
\end{tabular}

介

(iv) Fourth choice from four options [second worst]

\begin{tabular}{|l|}
\hline I don't do anything I value or enjoy with my time \\
\hline I have as much control over my daily life as I want \\
\hline Sometimes I can't look after myself well enough \\
\hline I feel less than adequately safe \\
\hline I have adequate social contact with people \\
\hline I have all the space and time I need to be myself \\
\hline I feel I have no encouragement and support \\
\hline
\end{tabular}

(ii) Second choice from six options [worst]

\begin{tabular}{|l|}
\hline I don't do anything I value or enjoy with my time \\
\hline I have as much control over my daily life as I want \\
\hline Sometimes I can't look after myself well enough \\
\hline I feel less than adequately safe \\
\hline I have adequate social contact with people \\
\hline I have all the space and time I need to be myself \\
\hline I feel I have no encouragement and support \\
\hline
\end{tabular}

(iii) Third choice from five options [second best]

\begin{tabular}{l} 
I don't do anything I value or enjoy with my time \\
I have as much control over my daily life as I want \\
\hline Sometimes I can't look after myself well enough \\
I feel less than adequately safe \\
I have adequate social contact with people \\
I have all the space and time I need to be myself \\
I feel I have no encouragement and support
\end{tabular}

Fig. 1 An example of a BWS profile using different QoL states from the ASCOT-Carer measure. OUniversity of Kent: The ASCOT-Carer measure is reproduced with permission from the University of Kent. All rights reserved

measure. The choice of the method used in [16] was informed by results from previous reviews $[38,39]$ which suggest that more information within choice sets can be obtained with less cognitive burden using the BWS method than using the DCE method. In the BWS profile case, one profile is presented at a time, and choices between alternatives are made within the displayed profile [40]. To reduce the effects of lexicographic and non-trading behaviour in the BWS tasks [41] and to obtain partial ranking for the attribute levels [39], the second-best and second-worst attribute levels from each profile were also selected (Fig. 1).
The full factorial design plan comprised $4^{7}$ possible profiles [38, 39]. To obtain a reasonable number of possible profiles to be presented to respondents, a fractional-factorial orthogonal main effects plan (OMEP) design of 32 profiles was used $[42,43]$. Each profile included seven attribute levels, one from each attribute defined in the ASCOT-Carer measure (Fig. 1). The profiles were randomly divided into four blocks of eight profiles. Each respondent randomly received an eight-profile block. Respondents first imagined a situation where they would have cared for a person who needed help in their daily lives due to old age, disability 
Table 2 Model developing process and specifications

\begin{tabular}{|c|c|c|c|c|}
\hline \multicolumn{2}{|c|}{ Estimation step } & \multirow{2}{*}{ Model } & \multirow{2}{*}{$\begin{array}{l}\text { Variable specification } \\
\text { Attribute levels and position variables of the attributes (for the best } \\
\text { or second-best choices, and for the worst and second-worst choices) } \\
\text { were included to the model }\end{array}$} & \multirow{2}{*}{$\begin{array}{l}\text { Result } \\
\text { Model [I] (Table 5) }\end{array}$} \\
\hline 1 & Basic model & & & \\
\hline 2 & Taste model & Mixed logit & $\begin{array}{l}\text { We included to the basic model (step 1): (a) the attribute-specific } \\
\text { constants (ASCs) for the worst or second-worst choices, and (b) the } \\
\text { interactions between the individual characteristics (e.g. age, gender, } \\
\text { education) and the attribute levels to explain taste heterogeneity. We } \\
\text { aimed to control for taste heterogeneity and minimise unexplained } \\
\text { variations }\end{array}$ & Not reported \\
\hline 3 & Taste-and-scale model & G-MNL & $\begin{array}{l}\text { We included to the taste model (step 2): different sets of } 4-5 \text { variables } \\
\text { at a time to investigate whether these variables could account for } \\
\text { scale heterogeneity }\end{array}$ & Not reported \\
\hline 4 & Scale model & S-MNL & $\begin{array}{l}\text { We kept the significant scale factors obtained from step } 3 \text { and the posi- } \\
\text { tion variables. We excluded the ASCs for the worst or second-worst } \\
\text { choices and the taste variables explaining taste heterogeneity }\end{array}$ & Model [II] (Table 5) \\
\hline \multirow[t]{2}{*}{5} & Taste-adjusted scale model & $\begin{array}{l}\text { S-MNL with } \\
\text { taste vari- } \\
\text { ables }\end{array}$ & $\begin{array}{l}\text { We included to the scale model (step 4) several significant interaction } \\
\text { terms (taste variables) to adjust taste differences between the sample } \\
\text { and general populations caused by the unrepresentative sampling }\end{array}$ & $\begin{array}{l}\text { Model [III] (Supple- } \\
\text { mental Table S1) }\end{array}$ \\
\hline & & & $\begin{array}{l}\text { Using results from Model [III], we derived final population-based } \\
\text { preference weights }\end{array}$ & Model [III*] (Table 5) \\
\hline
\end{tabular}

or illness. Then, they evaluated the alternatives in the profile and sequentially selected four alternatives that gave the greatest and lowest relative utilities, making a BWS choice task. The number of alternatives available per profile decreased after each choice and the best, worst, second-best and second-worst choices was sequentially made per profile in each BWS task before moving to the next profile and a new task (Fig. 1).

A foldover design was applied to reduce the number of easy choices from each profile [44]. To reduce selection bias, the blocked profiles were randomly assigned to respondents. The position (order) of attributes was randomised between (but not within) respondents to avoid ordering bias and disengage the effect of attribute choice from the position of that attribute within a choice task [16, 35, 45].

\section{Survey design and sampling}

An online survey that included the BWS experiment using the ASCOT-Carer measure was conducted between July and August 2016 and managed by Research Now. To achieve a representative sample of the Finnish general adult population for this survey, an online panel with quota sampling by age, gender and region was used. Besides the BWS choice data, we also collected information about respondents' demographic and socioeconomic background (such as gender, age, region, household income, education, marital status, religion, employment status and tenure), well-being (self-assessed health (SAH) and overall QoL), information on experience in caring and need for social care as well as information about how well the respondents understood the given BWS tasks.

Those who spent less than 4.5 min completing the BWS task section were excluded during the data collection. At a testing phase, we found that it took at least that amount of time to read and complete eight BWS tasks (32 choices). Due to power calculation requirements, we continued sampling until the target of 1000 participants was reached, but we obtained a slightly larger sample at the end of the data collection $(n=1009)$. Excluding those with no information on education $(n=4)$, the final sample consisted of 1005 respondents, and the long-format panel data had 32,160 choices.

\section{Modelling strategy}

The BWS choices were analysed based on the random utility theory $[33,46]$. The estimated preference parameters are a function of choice frequencies, and the choice of an attribute level describes the importance of that attribute level relative to other available attribute levels [40]. To start out estimating the coefficients of the attribute levels, we first applied a multinomial logit (MNL) model. As existing scale heterogeneity capturing the variance of the error term in a random utility model can distort preference estimates obtained from the MNL model [47], to account for differences in different subgroups' error variances and obtain more reliable and consistent preference estimates, we used a scale MNL (S-MNL) model [16, 38, 48] (Table 2).

To select appropriate scale factors for the S-MNL model, we sequentially estimated two specifications of the 
generalised MNL (G-MNL) model [48] before estimating the S-MNL model. The first model used observed respondent characteristics to investigate taste heterogeneity (hereafter, taste $M N L$ model). This was the MNL model expanded with (i) the attribute-specific constants (ASCs) for the worst or second-worst choices and (ii) interaction terms between attribute levels and observed characteristics of respondents to control for the variation in preferences for attribute levels between the subgroups of respondents. The second model, G-MNL, allowed for both taste heterogeneity and scale heterogeneity (hereafter, taste-and-scale MNL model). Hence, after having controlled for taste heterogeneity and minimised the unexplained variation of the model, we explored heterogeneity related to the error variance and selected the significant scale factors for the S-MNL model. Finally, a taste-adjusted S-MNL model was used to estimate population-based preference weights (described below). Table 2 describes the five-step modelling approach, and Appendix 1 describes the model specifications.

The models were estimated by maximum likelihood using the BIOGEME [49]. 'Apply runs' were conducted to detect significant variables capturing taste heterogeneity, using the ALOGIT [50]. Every model used level_4 of the CONT attribute, 'cont4', 'I have no control over my daily life' as a reference attribute level. The constant and position coefficients of the first attribute in the choice set for the best and worst choices were also assigned a value of zero to prevent over-identification. ${ }^{2}$ We applied sandwich estimators to get robust standard errors, accounting for the repeated choices [51].

\section{Scale factors and learning and fatigue effects}

To investigate scale factors, we included age, gender, education, SAH, overall QoL, experience in care, residential area, housing tenure, time to finalise eight BWS tasks and best and worst choices into the taste-and-scale MNL model (Table 2). Some of these factors were tested in Netten et al. [16]. We conducted a series of scale heterogeneity analyses with different subgroups of each variable for several sets of 4 or 5 potential scale variables to compare scale parameters and select scale variables. The final scale factors that were selected based on statistical significance $(p<0.05)$ were used in the S-MNL and taste-adjusted S-MNL models (Table 2).

The repeated and sequential choice tasks in choice experiments can cause fatigue and learning, affecting respondents' choice behaviour [34-36]. We expected that the position

\footnotetext{
$\overline{2}$ We included attribute-specific constants for the worst or secondworst choices into the mixed logit and G-MNL models. To avoid a saturated model, one attribute-specific constant was used as the reference constant.
}

of a choice task in a sequence of eight BWS choice tasks would be a scale factor explaining the error variance of the model. Following Carlsson et al. [34], we defined two identical sequences of four choice tasks in the BWS experiment. We tested the presence of fatigue or learning in the second sequence of four BWS choice tasks relative to the first sequence of four BWS choice tasks. Fatigue [learning] would mean that the respondents' choice behaviour is less consistent [more consistent] in the last four BWS tasks than in the first four BWS tasks. Correspondingly, for fatigue [learning] to occur, the variance of the error term of the S-MNL model is higher [lower] in the last four tasks than in the first four tasks [34, 52].

\section{Final preference estimates}

The preference weights should reflect the values of the Finnish general adult population. However, some socioeconomic and demographic covariates in the analysis sample were found to be over- or underrepresented compared to the general adult population ( $>10$ percentage points of $p<0.05)$. This occurred in three subgroups: house/apartment renters (from housing tenure), those with lower secondary education or below (from education), and those without any religion (from religion) (Table 3 ). The taste-adjusted S-MNL model-i.e. an S-MNL model that included significant interaction terms between attribute levels and the subgroups above-was estimated, from which the attribute level coefficients were adjusted for significant taste differences between the sample and general populations using modified post-stratification [53] to derive the final preference weights. This correction method was also applied in previous studies $[16,19,30,54,55]$. The standard errors of the adjusted, population-weighted preference weights were calculated using fixed population weights (Table 3) and the estimated variance-covariance matrix of the parameters of Model [III] provided by BIOGEME [49].

We normalised the attribute-level coefficients from different estimated models using the largest attribute-level coefficient as the common denominator. To better understand quantified changes in different ASCOT-QoL states, we linearly transformed the final 28 preference estimates to an index. We anchored the ASCOT-Carer index at a value of one for the set of states presented by the seven highest attribute-level coefficients (each per attribute) and a value of zero for the set of states presented by the seven lowest attribute-level coefficients (each per attribute), keeping the relative differences between the attribute-level coefficients unchanged. Thus, the ASCOT-Carer index measuring carers' SCRQoL ranges between zero and one, where one represents the best SCRQoL represented by the seven best ASCOT-QoL states (each per attribute) and zero represents the worst SCRQoL represented by the seven worst ASCOT-QoL states (each per attribute). 
Table 3 Analysis data characteristics vs. general population characteristics

\begin{tabular}{|c|c|c|c|c|c|}
\hline \multirow[t]{2}{*}{ Variable } & \multicolumn{2}{|c|}{ Analysis data $(n=1005)$} & \multicolumn{2}{|c|}{ General adult population } & \multirow[t]{2}{*}{ Source } \\
\hline & $\%$ & Freq. & $\%$ & Freq. & \\
\hline \multicolumn{6}{|l|}{ Socio-demographic variables } \\
\hline & & & 100 & $4,431,392$ & Statistics Finland (2016a) \\
\hline Female & 51.1 & 514 & 51.2 & $2,267,547$ & \\
\hline Age (in years) & & & 100 & $4,431,392$ & Statistics Finland (2016a) \\
\hline $18-24$ & 9.3 & 93 & 10.3 & 455,977 & \\
\hline $25-34$ & 15.7 & 158 & 15.9 & 704,402 & \\
\hline $35-44$ & 15.2 & 153 & 15.1 & 671,350 & \\
\hline $45-54$ & 18.3 & 184 & 16.1 & 712,553 & \\
\hline $55-64$ & 25.5 & 256 & 16.6 & 737,135 & \\
\hline $65-79$ & 15.4 & 155 & 19.4 & 861,876 & \\
\hline 80 or older & 0.6 & 6 & 6.5 & 288,099 & \\
\hline Marital status & & & 100 & $4,431,392$ & Statistics Finland (2016a) \\
\hline Married & 38.8 & 390 & 45.1 & $1,998,678$ & \\
\hline Divorced & 16.8 & 169 & 12.8 & 568,184 & \\
\hline Widowed & 3.3 & 33 & 6.4 & 282,794 & \\
\hline Single & 37.6 & 378 & 35.7 & $1,581,736$ & \\
\hline Prefer not to say & 3.5 & 35 & - & - & \\
\hline Education (ISCED 2011) & & & 100 & $4,591,285$ & Statistics Finland $(2015 a) \dagger$ \\
\hline Lower secondary or below $(\leq 2)$ & 10.8 & 109 & 18.8 & 667,598 & \\
\hline Upper secondary $(3,4)$ & 48.5 & 487 & 46.5 & $1,651,087$ & \\
\hline Short-cycle tertiary (5) & 10.4 & 105 & 10.5 & 373,847 & \\
\hline Bachelor's or equivalent (6) & 17.0 & 171 & 12.5 & 445,771 & \\
\hline Master's or equivalent (7) & 11.6 & 117 & 10.5 & 372,623 & \\
\hline Doctoral or equivalent (8) & 1.6 & 16 & 1.2 & 42,449 & \\
\hline Employment status & & & 100 & $4,431,392$ & Statistics Finland (2016b) \\
\hline Self-employed persons & 5.9 & 59 & 5.3 & 233,911 & \\
\hline Employees & 36.2 & 364 & 45.8 & $2,022,548$ & \\
\hline Students & 7.4 & 74 & 5.4 & 240,405 & \\
\hline Pensioners & 26.8 & 269 & 31.0 & $1,367,951$ & \\
\hline Unemployed & 15.9 & 160 & 8.5 & 374,534 & \\
\hline Others $^{\#}$ & 7.9 & 79 & 4.0 & 174,899 & \\
\hline Region & & & 100 & $4,407,913$ & Statistics Finland (2016a) ${ }^{\dagger}$ \\
\hline Helsinki and Uusimaa & 25.1 & 252 & 29.7 & $1,311,203$ & \\
\hline Southern Finland & 30.0 & 301 & 21.5 & 948,790 & \\
\hline Western Finland & 21.2 & 213 & 25.2 & $1,110,490$ & \\
\hline North-Eastern Finland & 23.8 & 239 & 23.5 & $1,037,430$ & \\
\hline Religion & & & 100 & $4,609,119$ & Statistics Finland $(2016 \mathrm{c})^{\dagger}$ \\
\hline No religion & 37.9 & 381 & 26.7 & $1,232,330$ & \\
\hline Any religion & 62.1 & 624 & 73.3 & $3,376,789$ & \\
\hline Housing tenure & & & 100 & $5,363,637$ & Statistics Finland $(2015 b) \dagger$ \\
\hline Own house or apartment & 53.4 & 537 & 70.8 & $3,804,549$ & \\
\hline Rent & 46.4 & 466 & 27.4 & 1,471,006 & \\
\hline Other & 0.2 & 2 & 1.9 & 101,544 & \\
\hline
\end{tabular}


Table 3 (continued)

\begin{tabular}{|c|c|c|c|c|c|}
\hline \multirow[t]{2}{*}{ Variable } & \multicolumn{2}{|c|}{$\begin{array}{l}\text { Analysis data } \\
(n=1005)\end{array}$} & \multicolumn{2}{|c|}{$\begin{array}{l}\text { General adult } \\
\text { population }\end{array}$} & \multirow[t]{2}{*}{ Source } \\
\hline & $\%$ & Freq. & $\%$ & Freq. & \\
\hline \multicolumn{6}{|l|}{ Annual household disposable cash income } \\
\hline$\leq 16,440 €(1$ st or 2 nd decile $)$ & 29.6 & 297 & & & \\
\hline $16,441 €-26,230 €(3 \mathrm{rd}$ or 4 th decile $)$ & 18.6 & 187 & & & \\
\hline $26,231 €-38,010 €(5$ th or 6 th decile $)$ & 15.5 & 156 & & & \\
\hline $38,011 €-54,690 €(7$ th or 8 th decile $)$ & 13.6 & 137 & & & \\
\hline$\geq 54,691 €(9$ th or 10 th decile $)$ & 10.9 & 110 & & & \\
\hline Prefer not to say or do not know & 11.7 & 118 & & & \\
\hline \multicolumn{6}{|l|}{ Health and well-being } \\
\hline Overall quality of life (QoL) & & & & & Murto et al. [67] \\
\hline So good or very good & 19.3 & 194 & 22.7 & & Very good \\
\hline Good & 47.9 & 481 & 54.9 & & Good \\
\hline Alright & 22.2 & 223 & 18.3 & & Neither good nor poor \\
\hline $\mathrm{Bad}$ & 8.4 & 84 & 3.5 & & Poor \\
\hline Very bad or so bad & 2.3 & 23 & 0.7 & & Very poor \\
\hline Self-assessed health (SAH) & & & & & Murto et al. [67] \\
\hline Very good & 7.9 & 79 & 29.9 & & Good \\
\hline Good & 46.1 & 463 & 36.2 & & Quite good \\
\hline Fair & 35.6 & 358 & 24.6 & & Fair \\
\hline $\mathrm{Bad}$ & 9.7 & 97 & 7.9 & & Quite bad \\
\hline Very bad & 0.8 & 8 & 1.5 & & $\mathrm{Bad}$ \\
\hline \multicolumn{6}{|l|}{ Experience of caring and need for social care } \\
\hline \multicolumn{6}{|l|}{$\begin{array}{l}\text { (i) Have you (personally) provided help or support to anyone } \\
\text { in the last month because they have long-term physical or } \\
\text { mental ill-health or disability, or problems relating to old age? }\end{array}$} \\
\hline Yes & 36.8 & 370 & & & \\
\hline No & 63.2 & 635 & & & \\
\hline \multicolumn{6}{|l|}{$\begin{array}{l}\text { (ii) Have either you or someone you are close to ever been in need } \\
\text { of any regular help and long-term care over the last } 10 \text { years? }\end{array}$} \\
\hline $\begin{array}{l}\text { Yes, I have or my partner/one of my parents has personal } \\
\text { experience }\end{array}$ & 36.2 & 364 & & & \\
\hline $\begin{array}{l}\text { Yes, one of my children/siblings or another relative/friend or an } \\
\text { acquaintance or a colleague or a neighbour }\end{array}$ & 23.8 & 239 & & & \\
\hline No experience with long-term care needs or do not know ${ }^{\&}$ & 40.0 & 402 & & & \\
\hline \multicolumn{6}{|l|}{ Understanding the tasks } \\
\hline \multicolumn{6}{|l|}{$\begin{array}{l}\text { (i) Did you feel that you could put yourself in the imaginary } \\
\text { situations described in the best-worst exercises? }\end{array}$} \\
\hline Yes, all of the time & 57.9 & 582 & & & \\
\hline Yes, but only some of the time & 38.7 & 389 & & & \\
\hline No & 3.4 & 34 & & & \\
\hline \multicolumn{6}{|l|}{ (ii) In the best-worst exercises, did you understand the situations? } \\
\hline Yes, all of them & 81.7 & 821 & & & \\
\hline Yes, but only some of them & 17.0 & 171 & & & \\
\hline No & 1.3 & 13 & & & \\
\hline
\end{tabular}

\#Those who were permanently sick or disabled, in community or military services, doing housework or outside of labour force

${ }^{\dagger}$ Religion (Statistics Finland 2016c) and education (Statistics Finland 2015a) refer to the population aged 15 or older. Housing tenure (Statistics Finland 2015b) refers to the whole housing population. Regions (Statistics Finland 2016a) refer to the population aged 18 or older. Household disposable cash income excluded imputed rents

\&Including 4\% of respondents who replied to response item "don't know" 
The transformation method has been used to anchor countryspecific preference weights [19, 30, 42, 55, 56].

\section{Results}

\section{Sample characteristics}

Compared to the general adult population, the analysis sample had more people aged 55-64 years, fewer who were employed, fewer people with the lowest educational level, a higher proportion of people with no religion (i.e. fewer people with some religion) and fewer homeowners (Table 3). $36.8 \%$ of respondents reported that they personally provided help or support to someone with long-term physical or mental ill-health or disability in the last month. Concerning how often respondents were able to put themselves in the imaginary situations described in the BWS exercises, $57.9 \%$ of them were able to do so all the time and $38.7 \%$ some of the time. Almost every respondent reported that they had understood the situations in the best-worst exercises all or some of the time $(98.7 \%)$ (Table 3$)$.

The cont1, occu2, occul and spacl attribute levels were mostly selected as the best or second-best (best, for simplicity's sake) choices (Table 4). The cont4, occu4, spac4 and safe 4 attribute levels were mostly chosen as the worst or second-worst (worst, for simplicity's sake) choices. The perc2 attribute level was preferred to the perc1 attribute level; perc 2 was selected more often than perc1 as the best or worst choice and in total. For the best choices, the further away from the 1st position in the profile an attribute level is, the less likely it was selected. For the worst choices, the likelihood of selecting an attribute level increased from the 1st to the 7 th position, but respondents seemed to be indifferent to the 3 rd or 4 th positions in the profile (Table 4).

\section{The preference estimates}

Results from the basic MNL (Model [I]) and S-MNL (Model [II]) and taste-adjusted S-MNL (Model [III*]) are reported in Table 5. In Model [III*], the coefficients of the occu3, safe4, socil and supp 4 attribute levels were adjusted to the significant taste differences between the sample and the general populations, all other estimated coefficients being the same as in Model [III] (Supplemental Table S1). Since pseudo- ${ }^{2}$ with values in the $[0.3 ; 0.4]$ range correspond to an $R^{2}$ with values in the [0.6; 0.8] range for an equivalent linear regression [57], the pseudo- $R^{2}$ of 0.289 presents a decent fit for Model [III*]. ${ }^{3}$

The inclusion of four scale factors substantially improved the goodness-of-fit of the model. The log-likelihood value increased from $-38,685.26$ (Model [I]) to $-38,475.50$

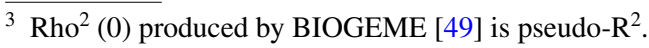

(Model [II]). The large increase in the log-likelihood value of Model [II] compared to Model [I] implied that it is very important to account for scale heterogeneity. Although the attribute-level coefficients from Models [II] and [Model III*] were quite similar, the latter was significantly better than the former by the log-likelihood ratio test ILR statistic $11.92=-2 \times(-38,457.50-(-38,469.54))$; $\mathrm{df}=47-43=4$; $p=0.018\}$ (Table 5). Below, we focus on the results from Model [III*] if not otherwise specified.

Across all attributes, the estimated attribute-level coefficients indicating their importance relative to cont4 were statistically significant. The three most-valued attribute levels were found within the control over daily life, occupation and space-and-time attributes (Fig. 2). The contl attribute level was the most-valued ASCOT-QoL state (coefficient 3.437). This was followed by the occul (3.343) and occu2 (3.336) attribute levels and the spacl (3.328) attribute level (Table 5). Furthermore, within each attribute, the bottom level (level_4) was the least-valued state. The least-valued attribute level, cont4, was followed by the spac4 (coefficient $0.287)$ and occu4 (0.303) attribute levels. The next three smallest valued states were the safe 4 (coefficient 0.608), perc4 (0.635) and soci4 (0.674) attribute levels.

Based on the magnitudes of the coefficients, the two top attribute levels were appreciated more than the two bottom attribute levels. Except for the SAFE attribute, the difference between attribute levels 1 and 2 was not significant at a $5 \%$ level of significance. In addition, a higher value was placed on the difference between attribute levels 2 and 3 (i.e. moving up from level_3 [some needs] to level_2 [no needs]) than on the difference between attribute levels 1 and 2 (i.e. moving up from level_2 to level_1 [ideal state]) and a higher value was also placed on the difference between attribute levels 3 and 4 than on the difference between attribute levels 1 and 2. Apart from the PERC attribute, the ordering of the attribute levels described by the magnitude of their estimated coefficients followed the ordering of four levels defined for each ASCOT-Carer attribute (Table 5, Fig. 2).

The result that the coefficient of the perc 2 attribute level was greater than that of the percl attribute level was unexpected. Due to this, we ran a new tasteadjusted S-MNL with the restriction that these coefficients were the same. This restriction did not have much influence on the estimated coefficients of the other attribute levels, while the new joint coefficient for percl and perc2 (Model [IV]) was the exact average of the coefficients of percl and perc2 (Model [III]) (Supplemental Table S1). Compared to the unrestricted model [III], the restricted model [IV] was also supported by the likelihood ratio test $(\mathrm{LR}$ statistic $=0.60$; $\mathrm{df}=1 ; p=0.436)$. However, to keep the order of the ASCOT attribute levels indicating the need intensity and ease the application of the preference weights, we 
Table 4 Descriptive statistics of attribute, attribute levels and position variables in the BWS tasks $(n=32,160)$

\begin{tabular}{|c|c|c|c|c|}
\hline & \multirow{3}{*}{ Name } & \multicolumn{3}{|c|}{ Descriptive value } \\
\hline & & \multicolumn{3}{|l|}{ Mean } \\
\hline & & All & $\begin{array}{l}\text { Best/2nd-best } \\
\text { choice }\end{array}$ & $\begin{array}{l}\text { Worst } / 2 \text { nd- } \\
\text { worst choice }\end{array}$ \\
\hline \multicolumn{5}{|l|}{ Attribute and level } \\
\hline Occupation & OCCU & 0.165 & 0.195 & 0.135 \\
\hline 1. I am able to spend my time as I want, doing things I value or enjoy. & occu1 & 0.045 & 0.085 & 0.005 \\
\hline 2. I am able do enough of the things I value or enjoy with my time. & occu2 & 0.045 & 0.085 & 0.005 \\
\hline 3. I do some of the things I value or enjoy with my time, but not enough. & occu3 & 0.027 & 0.020 & 0.034 \\
\hline 4. I do not do anything I value or enjoy with my time. & occu4 & 0.047 & 0.004 & 0.090 \\
\hline Control over daily life & CONT & 0.173 & 0.197 & 0.149 \\
\hline 1. I have as much control over my daily life as I want. & cont1 & 0.048 & 0.090 & 0.006 \\
\hline 2. I have adequate control over my daily life. & cont2 & 0.043 & 0.080 & 0.005 \\
\hline 3. I have some control over my daily life, but not enough. & cont3 & 0.030 & 0.023 & 0.037 \\
\hline 4. I have no control over my daily life. & cont 4 & 0.052 & 0.004 & 0.100 \\
\hline Looking after yourself & PERC & 0.135 & 0.122 & 0.148 \\
\hline 1. I look after myself as well as I want. & perc1 & 0.029 & 0.053 & 0.005 \\
\hline 2. I look after myself well enough. & perc2 & 0.030 & 0.055 & 0.006 \\
\hline 3. Sometimes I cannot look after myself well enough. & perc3 & 0.034 & 0.008 & 0.060 \\
\hline 4. I feel I am neglecting myself. & perc4 & 0.041 & 0.006 & 0.077 \\
\hline Safety & SAFE & 0.126 & 0.068 & 0.184 \\
\hline 1. I feel as safe as I want. & safe1 & 0.029 & 0.050 & 0.008 \\
\hline 2. Generally I feel adequately safe, but not as safe as I would like. & safe2 & 0.018 & 0.011 & 0.026 \\
\hline 3. I feel less than adequately safe. & safe3 & 0.036 & 0.004 & 0.068 \\
\hline 4. I do not feel at all safe. & safe4 & 0.043 & 0.003 & 0.082 \\
\hline Social participation and involvement & SOCI & 0.121 & 0.111 & 0.131 \\
\hline 1. I have as much social contact as I want with people I like. & soci1 & 0.030 & 0.053 & 0.007 \\
\hline 2. I have adequate social contact with people. & soci2 & 0.024 & 0.037 & 0.011 \\
\hline 3. I have some social contact with people, but not enough. & soci3 & 0.027 & 0.017 & 0.037 \\
\hline 4. I have little social contact with people and feel socially isolated. & soci4 & 0.040 & 0.004 & 0.076 \\
\hline Space and time to be yourself & SPAC & 0.168 & 0.190 & 0.147 \\
\hline 1. I have all the space and time I need to be myself. & spac1 & 0.044 & 0.084 & 0.005 \\
\hline 2. I have adequate space and time to be myself. & spac2 & 0.041 & 0.075 & 0.007 \\
\hline 3. I have some of the space and time I need to be myself, but not enough. & spac3 & 0.036 & 0.026 & 0.045 \\
\hline 4. I do not have any space or time to be myself. & spac4 & 0.047 & 0.005 & 0.090 \\
\hline Feeling supported and encouraged & SUPP & 0.112 & 0.118 & 0.107 \\
\hline 1. I feel I have the encouragement and support I want. & supp1 & 0.027 & 0.049 & 0.005 \\
\hline 2. I feel I have adequate encouragement and support. & supp2 & 0.031 & 0.051 & 0.011 \\
\hline 3. I feel I have some encouragement and support, but not enough. & supp3 & 0.018 & 0.012 & 0.024 \\
\hline 4. I feel I have no encouragement and support. & supp4 & 0.037 & 0.006 & 0.067 \\
\hline Attribute position & Name & Mean & Std. dev & \\
\hline \multicolumn{5}{|l|}{ For best/second-best choices } \\
\hline Attribute appeared in the 1 st row & pos1_B & 0.080 & 0.271 & \\
\hline Attribute appeared in the 2 nd row & pos2_B & 0.078 & 0.268 & \\
\hline Attribute appeared in the 3 rd row & pos3_B & 0.075 & 0.263 & \\
\hline Attribute appeared in the 4 th row & pos4_B & 0.073 & 0.259 & \\
\hline Attribute appeared in the 5 th row & pos5_B & 0.069 & 0.254 & \\
\hline Attribute appeared in the 6 th row & pos6_B & 0.063 & 0.243 & \\
\hline Attribute appeared in the 7 th row & pos7_B & 0.062 & 0.242 & \\
\hline
\end{tabular}


Table 4 (continued)

\begin{tabular}{|c|c|c|c|}
\hline Attribute position & Name & Mean & Std. dev \\
\hline \multicolumn{4}{|l|}{ For worst/second-worst choices } \\
\hline Attribute appeared in the 1 st row & pos1_W & 0.069 & 0.253 \\
\hline Attribute appeared in the $2 \mathrm{nd}$ row & pos2_W & 0.071 & 0.256 \\
\hline Attribute appeared in the $3 \mathrm{rd}$ row & pos3_W & 0.070 & 0.255 \\
\hline Attribute appeared in the 4 th row & pos4_W & 0.070 & 0.254 \\
\hline Attribute appeared in the 5 th row & pos5_W & 0.073 & 0.260 \\
\hline Attribute appeared in the 6 th row & pos6_W & 0.075 & 0.263 \\
\hline Attribute appeared in the 7 th row & pos7_W & 0.074 & 0.262 \\
\hline \multicolumn{4}{|l|}{ Scale variable } \\
\hline $\begin{array}{l}=1 \text { (good health) if the participant reported a very good or good health state, } \\
\text { and } 0 \text { otherwise (i.e. fair or bad or very bad health state) }\end{array}$ & hgood & 0.539 & 0.498 \\
\hline $\begin{array}{l}=1 \text { (long time) if the participant used more than } 6.5 \text { min to complete the BWS } \\
\text { tasks, and } 0 \text { otherwise (i.e. short time) })^{\#}\end{array}$ & tmlong & 0.750 & 0.433 \\
\hline $\begin{array}{l}=1 \text { (high education) if the participant had a Bachelor or Master or Doctoral or } \\
\text { equivalent degree, and } 0 \text { otherwise (i.e. low education, if she/he had a short- } \\
\text { cycle tertiary education or lower education) }\end{array}$ & eduhigh & 0.302 & 0.459 \\
\hline $\begin{array}{l}=1 \text { (learning) if being in the second sequence of four BWS tasks, } 0 \text { otherwise } \\
\text { (i.e. the first sequence of four BWS tasks) }\end{array}$ & learning & 0.500 & 0.500 \\
\hline
\end{tabular}

(OUniversity of Kent: the ASCOT-Carer measure is reproduced with permission from the University of Kent. All rights reserved

${ }^{\#}$ Time to complete the BWS task: $(\mathrm{p} 25 ; \mathrm{p} 50 ; \mathrm{p} 75 ;$ mean $)=(6.5 ; 8.7 ; 12.1 ; 23.4) \mathrm{min}$

used the preference estimates reported in Model [III*] (Table 5), from which we switched the order of the estimated coefficients of the percl and perc 2 attribute levels for the final preference weights to be used in practice (Table 6).

Significant position effects were found for the best choices. Compared to the top position of the presentation of the attributes, the coefficient of the second position variable (pos2_B) did not differ statistically significantly from that of the first position $(p>0.05)$. However, the coefficients of the position variables other than pos2_B were all statistically significant (Table 5). Moreover, the negative signs of the coefficients indicate that the respondents were less likely to choose an item in the profile that appeared after the second item from the top.

For the worst choices, the coefficients of the position variables were not statistically significant. The negative coefficients imply that the respondents were less likely to choose items located in the 6th and 5th rows of the profile than the items on the top or bottom rows when making their worst choices. Furthermore, except for pos2_W and pos2_B, the coefficients of the position variables were of lower magnitude for the worst choices than for the best choices. The results imply that the position effect was more strongly related to the best choices than to the worst choices, other things remaining constant, which was in agreement with the result from a discrete choice experiment [58].

\section{The scale factors and learning effect}

The estimated parameter for the learning scale factor exceeds 1 (Table 5). We thus found a lower error variance for the second sequence of four tasks relative to the first sequence of four tasks, suggesting that the respondent responses were more consistent in the last four tasks than in the first four tasks, i.e. that learning took place in the sequential BWS choice experiment. Our finding is consistent with that by Carlsson et al. [33], who explored learning and fatigue effects in the context of a choice experiment concerning food safety.

Regarding other scale factors, respondents who had better SAH, or a high level of education or spent more time ( $>6.5 \mathrm{~min}$ ) doing the BWS tasks were more consistent in their choices than those who had worse (i.e. fair, bad or very bad) SAH, or a lower level of education or spent less time ( $\leq 6.5 \mathrm{~min}$ ) doing the BWS tasks (Table 5). The latter two scale factors were in line with the results in Batchelder et al. [19].

\section{The final preference weights}

Table 6 reports the normalised and rescaled values (i.e. preference-based index values) of the attribute-level coefficients for the Finnish ASCOT-Carer measure. Due to differences between the attribute-level coefficients and the average value of all lowest rated attribute levels $[42,55]$, the rescaled values can also be negative. The originally 
Table 5 Estimated preference parameters for the Finnish ASCOT for carers $(n=32,160)$

\begin{tabular}{|c|c|c|c|c|c|c|c|c|c|}
\hline & \multicolumn{3}{|l|}{ Model $[I]^{1}$} & \multicolumn{3}{|l|}{ Model $[\mathrm{II}]^{1}$} & \multicolumn{3}{|c|}{ Model $\left[\mathrm{III}^{*}\right]^{1,2}$} \\
\hline & Estimated & Robust & Normalised & Estimated & Robust & Normalised & Estimated & Robust & Normalised \\
\hline & Coeff. & $t$-value & Coeff. & Coeff. & $t$-value & Coeff. & Coeff. & $t$-value & Coeff. \\
\hline \multicolumn{10}{|c|}{ Occupation (OCCU) } \\
\hline occu1 & 4.617 & 37.18 & 0.973 & 3.351 & 15.46 & 0.976 & 3.353 & 15.46 & 0.976 \\
\hline occu 2 & 4.582 & 37.76 & 0.965 & 3.333 & 15.66 & 0.970 & 3.336 & 15.65 & 0.971 \\
\hline occu3 & 2.211 & 31.54 & 0.466 & 1.597 & 14.76 & 0.465 & 1.592 & 14.46 & 0.463 \\
\hline occu 4 & 0.433 & 8.75 & 0.091 & 0.302 & 7.67 & 0.088 & 0.303 & 7.67 & 0.088 \\
\hline \multicolumn{10}{|c|}{ Control over daily life (CONT) } \\
\hline cont 1 & 4.746 & 36.16 & 1.000 & 3.435 & 15.32 & 1.000 & 3.437 & 15.31 & 1.000 \\
\hline cont2 & 4.439 & 37.34 & 0.935 & 3.232 & 15.58 & 0.941 & 3.235 & 15.57 & 0.941 \\
\hline cont 3 & 2.227 & 28.68 & 0.469 & 1.603 & 14.39 & 0.467 & 1.604 & 14.38 & 0.467 \\
\hline cont 4 & 0.000 & ref. & 0.000 & 0.000 & ref. & 0.000 & 0.000 & ref. & 0.000 \\
\hline \multicolumn{10}{|c|}{ Looking after yourself (PERC) } \\
\hline perc1 & 3.773 & 36.72 & 0.795 & 2.756 & 15.67 & 0.802 & 2.758 & 15.67 & 0.802 \\
\hline perc2 & 3.813 & 36.05 & 0.803 & 2.782 & 15.58 & 0.810 & 2.784 & 15.58 & 0.810 \\
\hline perc3 & 1.290 & 20.37 & 0.272 & 0.935 & 13.01 & 0.272 & 0.936 & 13.01 & 0.272 \\
\hline perc4 & 0.889 & 15.13 & 0.187 & 0.634 & 11.18 & 0.185 & 0.635 & 11.17 & 0.185 \\
\hline \multicolumn{10}{|c|}{ Safety (SAFE) } \\
\hline safe1 & 3.642 & 36.71 & 0.767 & 2.647 & 15.55 & 0.771 & 2.648 & 15.55 & 0.770 \\
\hline safe2 & 2.336 & 32.80 & 0.492 & 1.683 & 15.00 & 0.490 & 1.684 & 15.00 & 0.490 \\
\hline safe 3 & 1.138 & 18.85 & 0.240 & 0.810 & 12.16 & 0.236 & 0.811 & 12.16 & 0.236 \\
\hline safe4 & 0.778 & 13.17 & 0.164 & 0.563 & 10.39 & 0.164 & 0.608 & 10.29 & 0.177 \\
\hline \multicolumn{10}{|c|}{ Social participation and involvement (SOCI) } \\
\hline soci1 & 3.766 & 34.82 & 0.794 & 2.741 & 15.42 & 0.798 & 2.758 & 15.20 & 0.803 \\
\hline soci2 & 3.344 & 33.89 & 0.705 & 2.439 & 15.51 & 0.710 & 2.440 & 15.50 & 0.710 \\
\hline soci3 & 2.203 & 31.03 & 0.464 & 1.584 & 14.83 & 0.461 & 1.586 & 14.82 & 0.461 \\
\hline soci4 & 0.935 & 16.46 & 0.197 & 0.674 & 11.70 & 0.196 & 0.674 & 11.69 & 0.196 \\
\hline \multicolumn{10}{|c|}{ Space and time to be yourself (SPAC) } \\
\hline spac1 & 4.579 & 37.82 & 0.965 & 3.326 & 15.69 & 0.968 & 3.328 & 15.69 & 0.968 \\
\hline spac2 & 4.307 & 37.27 & 0.908 & 3.149 & 15.71 & 0.917 & 3.151 & 15.70 & 0.917 \\
\hline spac3 & 2.118 & 29.50 & 0.446 & 1.528 & 14.62 & 0.445 & 1.530 & 14.61 & 0.445 \\
\hline spac4 & 0.397 & 7.84 & 0.084 & 0.287 & 7.21 & 0.084 & 0.287 & 7.20 & 0.083 \\
\hline \multicolumn{10}{|c|}{ Feeling supported and encouraged (SUPP) } \\
\hline supp1 & 3.662 & 36.37 & 0.772 & 2.665 & 15.55 & 0.776 & 2.667 & 15.54 & 0.776 \\
\hline supp2 & 3.660 & 35.08 & 0.771 & 2.662 & 15.42 & 0.775 & 2.664 & 15.41 & 0.775 \\
\hline supp3 & 2.228 & 30.92 & 0.469 & 1.611 & 15.06 & 0.469 & 1.612 & 15.06 & 0.469 \\
\hline supp4 & 1.097 & 18.36 & 0.231 & 0.779 & 12.27 & 0.227 & 0.798 & 12.19 & 0.232 \\
\hline \multicolumn{10}{|c|}{ Position for best/second-best choices } \\
\hline pos2_B & -0.050 & -1.18 & & -0.029 & -0.95 & & -0.029 & -0.96 & \\
\hline pos3_B & -0.148 & -3.34 & & -0.109 & -3.38 & & -0.109 & -3.38 & \\
\hline pos4_B & -0.220 & -4.98 & & -0.151 & -4.67 & & -0.151 & -4.67 & \\
\hline pos5_B & -0.276 & -5.86 & & -0.194 & -5.49 & & -0.194 & -5.49 & \\
\hline pos6_B & -0.414 & -9.18 & & -0.285 & -7.78 & & -0.285 & -7.78 & \\
\hline pos7_B & -0.412 & -8.79 & & -0.288 & -7.82 & & -0.288 & -7.82 & \\
\hline \multicolumn{10}{|c|}{ Position for worst/second-worst choices } \\
\hline pos2_W & -0.047 & -1.07 & & -0.036 & -1.12 & & -0.036 & -1.13 & \\
\hline pos3_W & -0.017 & -0.38 & & -0.008 & -0.24 & & -0.007 & -0.22 & \\
\hline pos4_W & 0.041 & 0.93 & & 0.035 & 1.08 & & 0.034 & 1.07 & \\
\hline
\end{tabular}


Table 5 (continued)

\begin{tabular}{|c|c|c|c|c|c|c|c|c|c|}
\hline & \multicolumn{3}{|l|}{ Model $[\mathrm{I}]^{1}$} & \multicolumn{3}{|l|}{ Model $[\mathrm{II}]^{1}$} & \multicolumn{3}{|c|}{ Model [III*] $]^{1,2}$} \\
\hline & Estimated & Robust & Normalised & Estimated & Robust & Normalised & Estimated & Robust & Normalised \\
\hline & Coeff. & $t$-value & Coeff. & Coeff. & $t$-value & Coeff. & Coeff. & $t$-value & Coeff. \\
\hline pos5_W & -0.058 & -1.27 & & -0.039 & -1.19 & & -0.041 & -1.24 & \\
\hline pos6_W & -0.064 & -1.37 & & -0.042 & -1.25 & & -0.043 & -1.29 & \\
\hline pos7_W & -0.034 & -0.74 & & -0.025 & -0.74 & & -0.026 & -0.77 & \\
\hline \multicolumn{10}{|l|}{ Scale factor } \\
\hline hgood & & & & 1.120 & 2.13 & & 1.120 & 2.13 & \\
\hline eduhigh & & & & 1.244 & 3.69 & & 1.243 & 3.63 & \\
\hline tmlong & & & & 1.241 & 3.23 & & 1.240 & 3.21 & \\
\hline learning & & & & 1.069 & 3.88 & & 1.069 & 3.93 & \\
\hline Observations & & 32,160 & & & 32,160 & & & 32,160 & \\
\hline Degree of freedom & & 39 & & & 43 & & & 47 & \\
\hline Log-likelihood value & & $-38,685.26$ & & & $-38,475.50$ & & & $-38,469.54$ & \\
\hline $\mathrm{Rho}^{2}(0)$ & & 0.285 & & & 0.288 & & & 0.289 & \\
\hline
\end{tabular}

${ }^{1}$ Model $[\mathrm{I}]=$ basic MNL. Model [II] =S-MNL. Final preference weights reported in Model [III*] were derived using results from Model [III] (taste-adjusted S-MNL) (Supplemental Table S1)

${ }^{2}$ We corrected the coefficients of occu3, safe4, soci1, and supp4 attribute levels and computed their robust $t$-values

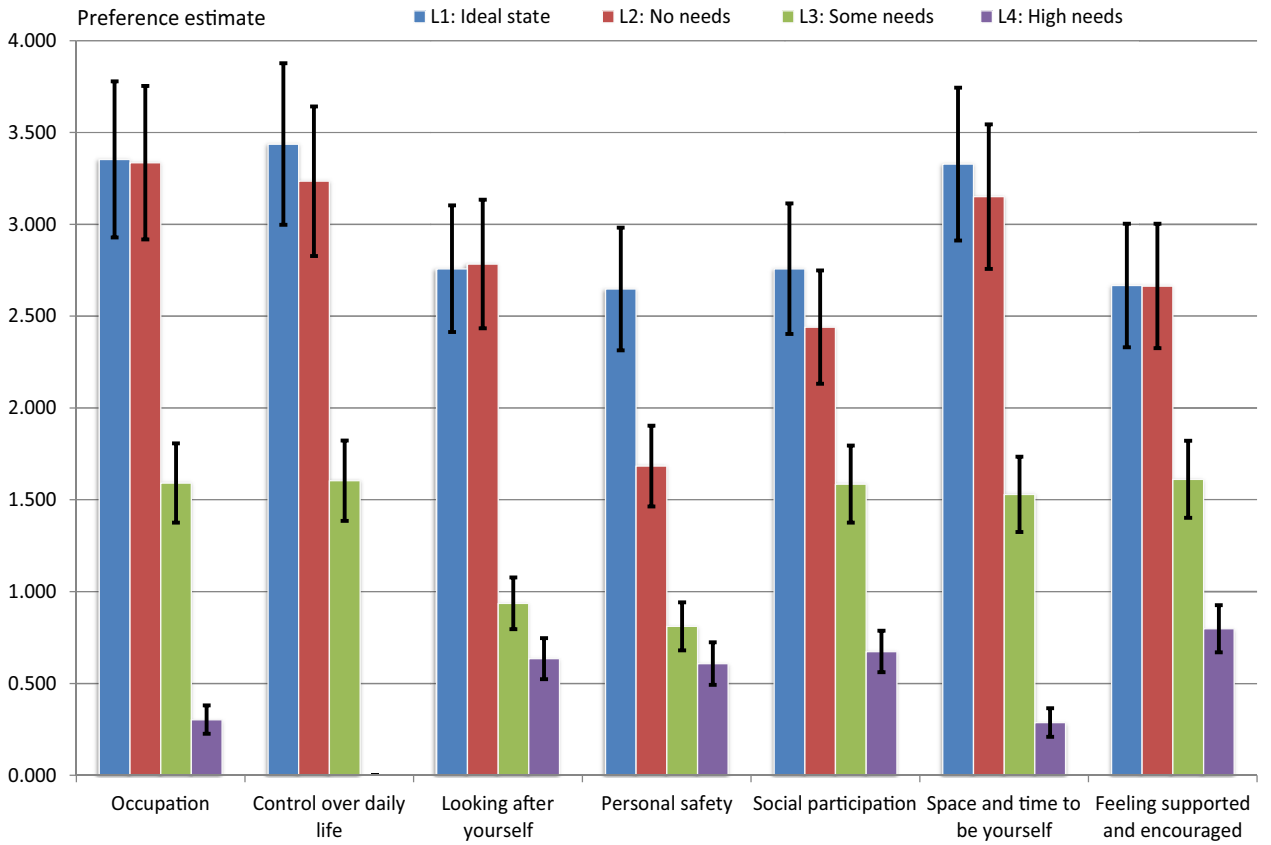

Fig. 2 The attribute-level coefficients and their 95\% confidence interval for the Finnish ASCOT for carers measure

estimated coefficients of the percl and perc2 attribute levels were switched, as discussed above (Table 6).

Preference-based index values for the Finnish ASCOT-Carer measure can be used to measure changes in carers' SCRQoL, for instance, due to targeted interventions aiming to improve carers' QoL (Table 6). Since the ASCOT-Carer index is additive, an improvement in the ASCOT-QoL of an individual-for example, from an inferior state of 3442434 to an improved state of 1231321 -would suggest a change in value from 0.204 $[=0.063+(-0.027)+0.009+0.069+0.011+0.069+$ $0.018]$ to $0.808[=0.163+0.156+0.026+0.123+0.06$ 
Table 6 Values of the Finnish preference weights for the ASCOT for carers' measure

\begin{tabular}{lllllllll}
\hline $\begin{array}{l}\text { Value of preference } \\
\text { weight }\end{array}$ & $\begin{array}{l}\text { Level and } \\
\text { meaning }\end{array}$ & Occupation & $\begin{array}{l}\text { Control over } \\
\text { daily life }\end{array}$ & $\begin{array}{l}\text { Looking } \\
\text { after } \\
\text { yourself }\end{array}$ & $\begin{array}{l}\text { Personal } \\
\text { safety }\end{array}$ & $\begin{array}{l}\text { Social } \\
\text { participation }\end{array}$ & $\begin{array}{l}\text { Space and } \\
\text { time }\end{array}$ & $\begin{array}{l}\text { Feeling } \\
\text { supported and } \\
\text { encouraged }\end{array}$ \\
\hline Panel 1. & 1 Ideal state & 0.976 & 1.000 & 0.810 & 0.770 & 0.803 & 0.968 & 0.776 \\
$\quad \begin{array}{l}\text { Normalised } \\
\text { values }\end{array}$ & 2 No needs & 0.971 & 0.941 & 0.802 & 0.490 & 0.710 & 0.917 & 0.775 \\
& 3 Some needs & 0.463 & 0.467 & 0.272 & 0.236 & 0.461 & 0.445 & 0.469 \\
& 4 High needs & 0.088 & 0.000 & 0.185 & 0.177 & 0.196 & 0.083 & 0.232 \\
\hline Panel 2. & 1 Ideal state & 0.163 & 0.168 & 0.131 & 0.123 & 0.129 & 0.162 & 0.124 \\
Preference-based & 2 No needs & 0.162 & 0.156 & 0.129 & 0.069 & 0.111 & 0.152 & 0.124 \\
index values & 3 Some needs & 0.063 & 0.064 & 0.026 & 0.019 & 0.063 & 0.060 & 0.065 \\
& 4 High needs & -0.010 & -0.027 & 0.009 & 0.008 & 0.011 & -0.011 & 0.018 \\
\hline
\end{tabular}

Note. For the looking after yourself attribute, the current preference weight of level_1 was the originally estimated preference weight of level_2 and the current preference weight of level_2 was the originally estimated preference weight of level_1

\section{FIN better state $\quad$ FIN poorer state}

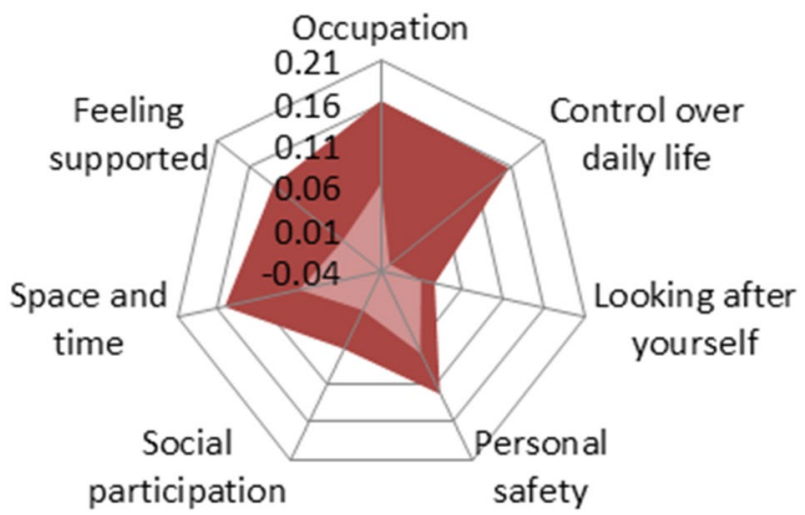

Fig. 3 Changes in the Finnish preference-based index values for the ASCOT-Carer measure from a poorer state (3442434) to a better state (1231321). Preference-based index values for the Finnish version of the ASCOT-Carer measure were derived in this study (Table 6). The state of 3442434 consisted of occu3, cont4, perc4, safe2, soci4, space3, and supp 4 attribute levels and that of 1231321 consisted of occu1, cont2, perc3, safe1, soci3, space2, and supp1 attribute levels

$3+0.152+0.124] .{ }^{4}$ This gain in SCRQoL is illustrated as the area between two acreages covered by two radars in Fig. 3. Although with a different scale, a similar figure can be drawn using the normalised values. Those who would like to utilise our developed preference

\footnotetext{
4 The attribute levels indicated the intensity of needs: $1=$ ideal state; $2=$ no needs; $3=$ some needs; and $4=$ high needs. The attributes were specified in the order: 1. Occupation (OCCU), 2. Control over daily life (CONT), 3. Looking after yourself (PERC), 4. Personal safety (SAFE), 5. Social participation (SOCI), 6. Space and time (SPAC), and 7. Feeling supported and encouraged (SUPP). The state of 3442434 consisted of occu3, cont4, perc4, safe2, soci4, space3, and supp 4 attribute levels and that of 13121 consisted of occul, cont 2 , perc3, safe1, soci3, space2, and supp1 attribute levels.
}

weights can use the normalised or rescaled values of the final preference weights in evaluations involving the Finnish ASCOT-Carer measure (Table 6).

\section{Discussion}

In this study, we derived the population-based preference weights for the Finnish version of the ASCOT-Carer measure, which was translated from the English ASCOT-Carer measure [18] to Finnish in 2015-2016 [31]. The BWS choice data were analysed using an S-MNL model, considering the significant taste differences between the sample and general adult populations. Moreover, we provided evidence on the learning effect in the BWS experiment.

Both the most and least-valued attribute levels of the Finnish ASCOT-Carer measure were found in the occupation, control and space-and-time attributes. Compared to English preference weights that were derived using a similar analysis framework [19], Finnish respondents valued most highly the attribute levels within the control, occupation and space-andtime attributes (Supplemental Figure O1). The most preferred attribute level was contl state in Finland, while it was occul in England. For both countries, the least preferred attribute level was the cont 4 state with a negative preference-based index value: -0.027 (Finland) and -0.012 (England). Although the rank order of the derived preference weights is similar between the two countries, there are clear differences in the magnitude of the country-specific preference weights, which could stem from differences in the country-specific populations' preferences and values or norms. These differences justify the contribution of this paper to developing the Finnish preference weights for the Finnish ASCOT-Carer measure.

The significant position effect we found for the best choices was in line with the English [19] and Austrian [30] studies. To mitigate position bias affecting choice behaviour and decision rules, which can result in invalid coefficient 
estimates, the position of the attributes in the BWS profiles should be rotated to ensure that each item will appear an equal number of times in each profile. This was earlier noted by Campbell and Erdem [58]. Since the position effect can bring about invalid preference estimates [34], in addition to randomisation at the experimental design stage, researchers can include position-specific constants of the attributes into the model to account for the order of the profiles.

The significant scale factors found in this study suggest that researchers should account for scale heterogeneity because varying error variance across different sample population groups can distort preference estimates [47]. This also calls for approaches that can disentangle scale heterogeneity from taste heterogeneity to make accurate estimates about people's preferences [59]. This, in turn, supports our approach of investigating taste heterogeneity first (using the mixed logit with observed characteristics of respondents) and then scale heterogeneity after having controlled for taste heterogeneity (using the G-MNL) before obtaining the final preference estimates from the S-MNL model.

Education and health as scale factors are known to be related to cognitive functioning [42,60]. Besides implying the use of heuristics to quickly make choices [61], short response times can imply respondents' reduced effort to engage in the BWS tasks or to properly consider the available alternatives. The evidence of the learning effect in the sequential BWS choice experiment is consistent with the previous choice experimental studies [52,62]. As we had two identical sequences of four BWS tasks, the finding implies the more consistent responses in the second half of the experiment than in the first half. We also tested other sequential divisions of the BWS choice tasks as a scale factor (such as 1 task vs. 7 tasks; 2 tasks vs. 6 tasks; 3 tasks vs. 5 tasks), but they were not statistically significant. The learning effect implies that future studies that collect and use sequential choice data should develop study designs that can reduce possible preference uncertainty at the beginning of the experiment and increase respondent engagement throughout the experiment. Concerning scale heterogeneity, researchers can account for the effect of learning and fatigue on the preference estimates by explicitly modelling learning or fatigue as a scale factor using the sequences of the BWS tasks.

There is evidence that modes of survey administration, such as Internet-based surveys, might result in stronger fatigue effects and weaker learning effects [36]. Although the survey including the BWS experiment was Internet based, we found the learning effect. Prominent differences in the preferences for SCRQoL from two models, which used online BWS data and face-to-face interview data, were not observed [63]. The final pattern of learning and fatigue as a research question is beyond the scope of this study. However, it might be relevant to investigate in more detail the potential impact of the learning effects on preference stability and how learning styles and preference uncertainty vary between the individuals [34]. The found learning effect would suggest that these issues could extend to also consider the BWS method in different survey administration modes.

This study contributes to expanding the number of valid measures that can be used to evaluate capability-based QoL in a general population [37] and to consider the evaluation of outcomes and interventions beyond health [64, 65]. Since the ASCOT [16] focuses on measuring care recipients' SCRQoL and the ASCOT-Carer [19] focuses on measuring caregivers' SCRQoL, both measures can be in use for the evaluation of social care interventions. Finnish preference weights for the ASCOT measure have been established [29].

Our study has some limitations. Despite the use of sampling quotas, the online panel was not fully representative regarding housing tenure, education and religion. However, we adjusted the preference weights to better reflect the values of the Finnish general adult population, which was done in the studies $[19,30]$, but in addition, we computed the standard errors of the adjusted final preference estimates, which was not carried out in the mentioned studies. With the used survey administration method, we were not able to monitor external and internal incentives or impetuses during the BWS experiment, such as the respondents' behaviour, engagement and burden, and changes in the task environment. Nevertheless, respondents who spent less than 4.5 min doing the BWS tasks were excluded during the data collection phase.

We have successfully derived the Finnish preference weights for the Finnish ASCOT-Carer measure. The preference weights established here will enable researchers in Finland, for the first time, to consider the value of different social care interventions for evaluating support and services to informal carers. The learning effect, as one of the significant scale factors, implies not only the importance of accounting for scale heterogeneity in the choice experiments but also that future studies with sequential choice tasks should develop study designs such that they ensure equal consideration to all choice tasks (or profiles) for the attributes in the profiles to reduce potential preference uncertainty at the beginning of the experiment and increase respondent engagement in the experiment.

\section{Appendix 1}

\section{Model specifications}

Based on random utility theory, the utility associated with chosen attribute $j$ that individual $i$ gets, $U_{\mathrm{ij}}$, is given by an explained (systematic) component, $V_{\mathrm{ij}}$, and a random (error) component, $\xi_{i j}$ [48]: 
$U_{i j}=V_{i j}+\left(\xi_{i j} / \lambda\right)$.

The scale parameter $\lambda$ is inversely proportional to the standard error of the error term, allowing the variance of the error term to vary across different subpopulations in the data. The higher the value of $\lambda$, the lower the error variance of the random utility model is, implying more consistent choices. However, in the basic MNL model, $\lambda$ is set to unity. In addition, the explained component was modelled as follows:

$V_{i j}=\sum_{p=1}^{7} \alpha_{p}^{b} z^{b}+\sum_{p=1}^{7} \alpha_{p}^{w} z^{w}+\sum_{p=1}^{7} \sum_{q=1}^{4} \beta_{p q} x_{p q}$,

where $x$ stands for an attribute level that was independently and sequentially selected, $\beta_{\mathrm{pq}}$ represents the effect of the qth level ( 1 ideal state, 2 no needs, 3 some needs, 4 high needs) over the pth attribute ( 1 occupation, 2 control over daily life, 3 looking after yourself, 4 safety, 5 social participation and involvement, 6 space and time to be yourself, 7 feeling supported and encouraged). $\mathrm{z}^{\mathrm{b}}$ [or $\mathrm{z}^{\mathrm{w}}$ ] stands for dummy variables that were associated with the position (or order) of the attribute chosen as the best or second-best [or worst or second-worst] within the choice set; $\alpha_{p}^{b}\left[\right.$ or $\left.\alpha_{p}^{w}\right]$ is the position (or ordering) effect of the pth attribute for the best or second-best [or worst or second-worst] choices.

Assuming that the error term in model (1) is independently and identically type I extreme-value distributed, the probability that an individual $i$ chooses alternative $j$ from all the possible alternatives $s$ in a choice set $S$ is given as [51]:

$P_{i j}=\frac{\exp \left(\lambda V_{i j}\right)}{\sum_{s \in S} \exp \left(\lambda V_{i s}\right)}$.

To simultaneously analyse "worst" and "best" choice data, the utility of the "worst" or "second-worst" (hereafter "worst") choice has a sign opposite to the sign of the utility associated with the "best" or "second-best" (hereafter "best") choice, while the utility functions for both types of choices are similar [40]. In each estimated model, we included as basic explanatory variables the attribute levels and variables describing attribute-positions for the best and worst choices. The latter allowed for the overall effects of attribute ordering associated with the experimental task design $[58,66]$. Owing to scale factors, the number of parameters estimated by an S-MNL will be higher than that by a basic MNL.

Supplementary Information The online version contains supplementary material available at https://doi.org/10.1007/s10198-021-01356-3.

Acknowledgements The EXCELC project was funded by the NORFACE Welfare State Futures programme under Grant Number
462-14-160. The Finnish contribution to the project was co-funded by the Finnish Institute for Health and Welfare (THL), Finland and the Austrian contribution by the Austrian Science Fund (FWF, Project Number I 2252-G16) and the Vienna Social Fund (FSW), Austria. The views expressed were not necessarily those of the funders.

Author contributions LN: methodology, software, validation, formal analysis, investigation, data curation, writing-original draft preparation, writing - reviewing and editing, and visualisation. $\mathrm{HJ}$ : formal analysis, investigation, software, and validation. IL: conceptualization, resources, writing - reviewing and editing, supervision, funding acquisition, and project administration. E-CS: software, formal analysis, writing-reviewing and editing. LB: software, formal analysis, writing - reviewing and editing. JM: conceptualization, methodology, resources, data curation, writing - reviewing and editing, funding acquisition, and project administration. HL: methodology, writingreviewing and editing. PB: methodology, writing-reviewing and editing, and funding acquisition. BT: conceptualization, resources, writing-reviewing and editing, funding acquisition, and project administration. JF: conceptualization, supervision, funding acquisition, and project administration.

Funding Open access funding provided by Finnish Institute for Health and Welfare (THL).

Data availability Data are confidential and are not available for public use.

\section{Declarations}

Ethical approval Ethical approval for the study was obtained from the Finnish Institute for Health and Welfare (THL), Finland in February 2016.

Open Access This article is licensed under a Creative Commons Attribution 4.0 International License, which permits use, sharing, adaptation, distribution and reproduction in any medium or format, as long as you give appropriate credit to the original author(s) and the source, provide a link to the Creative Commons licence, and indicate if changes were made. The images or other third party material in this article are included in the article's Creative Commons licence, unless indicated otherwise in a credit line to the material. If material is not included in the article's Creative Commons licence and your intended use is not permitted by statutory regulation or exceeds the permitted use, you will need to obtain permission directly from the copyright holder. To view a copy of this licence, visit http://creativecommons.org/licenses/by/4.0/.

\section{References}

1. OECD: Informal carers: In: ealth at a Glance 2017: OECD indicators. OECD Publishing (2017)

2. Greve, B. (Ed.): Long-term care for the elderly in Europe: development and prospects (1st ed.). Routledge. (2016). https://doi.org/ $10.4324 / 9781315592947$

3. Barbieri, D., Ghibelli, P. (eds.): Formal versus informal longterm care: economic and social impacts. SPRINT Working Paper D4.4. SPRINT, Brussels (2019). http://sprint-project.eu/wp-conte nt/uploads/2018/09/SPRINT_D4.4_Formal_vs_Informal-LTC_ Economic_Social_Impacts.pdf. Accessed 29 June 2019 
4. Savage, S., Bailey, S.: The impact of caring on caregivers' mental health: a review of the literature. Aust. Health Rev. 27, 111-117 (2004). https://doi.org/10.1071/ah042710111

5. Colombo, F., et al.: Help Wanted? OECD Publishing (2011). https://doi.org/10.1787/9789264097759-en. Accessed 10 Jan 2021

6. Bauer, J.M., Sousa-Poza, A.: Impacts of informal caregiving on caregiver employment, health, and family. J. Popul. Age. 8, 113-145 (2015). https://doi.org/10.1007/s12062-015-9116-0

7. Kumagai, N.: Distinct impacts of high intensity caregiving on caregivers' mental health and continuation of caregiving. Health Econ. Rev. 7, 15-15 (2017). https://doi.org/10.1186/ s13561-017-0151-9

8. van den Berg, B., Fiebig, D.G., Hall, J.: Well-being losses due to care-giving. J. Health Econ. 35, 123-131 (2014). https://doi. org/10.1016/j.jhealeco.2014.01.008

9. Do, Y.K., Norton, E.C., Stearns, S.C., Van Houtven, C.H.: Informal care and caregiver's health. Health Econ. 24, 224-237 (2015). https://doi.org/10.1002/hec.3012

10. Hudson, P.L., Trauer, T., Graham, S., Grande, G., Ewing, G., Payne, S., Stajduhar, K.I., Thomas, K.: A systematic review of instruments related to family caregivers of palliative care patients. Palliat. Med. 24, 656-668 (2010). https://doi.org/10. $1177 / 0269216310373167$

11. Harvey, K., Catty, J., Langman, A., Winfield, H., Clement, S., Burns, E., White, S., Burns, T.: A review of instruments developed to measure outcomes for carers of people with mental health problems. Acta Psychiatr Scand 117, 164-176 (2008). https://doi.org/10.1111/j.1600-0447.2007.01148.x

12. Zarit, S.H., Reever, K.E., Bach-Peterson, J.: Relatives of the impaired elderly: correlates of feelings of burden. Gerontologist 20, 649-655 (1980). https://doi.org/10.1093/geront/20.6.649

13. Radloff, L.S.: The CES-D scale: a self-report depression scale for research in the general population. Appl. Psychol. Meas. 1, 385-401 (1977). https://doi.org/10.1177/014662167700100306

14. George, L.K., Gwyther, L.P.: Caregiver well-being: a multidimensional examination of family caregivers of demented adults. Gerontologist 26, 253-259 (1986). https://doi.org/10.1093/geront $/ 26.3 .253$

15. Goodrich, K., Kaambwa, B., Al-Janabi, H.: The inclusion of informal care in applied economic evaluation: a review. Value Health 15, 975-981 (2012). https://doi.org/10.1016/j.jval.2012. 05.009

16. Netten, A., Burge, P., Malley, J., Potoglou, D., Towers, A.-M., Brazier, J., Flynn, T., Forder, J., Wall, B.: Outcomes of social care for adults: developing a preference-weighted measure. Health Technol. Assess. 16, 1-166 (2012). https://doi.org/10.3310/hta16 160

17. Malley, J., Fox, D., Netten, A.: Developing a carers' experience performance indicator. PSSRU Discussion Paper 2734. University of Kent, Kent (2010). https://kar.kent.ac.uk/77660/2/dp2734.pdf. Accessed 22 June 2019

18. Rand, S.E., Malley, J.N., Netten, A.P., Forder, J.E.: Factor structure and construct validity of the adult social care outcomes toolkit for carers (ASCOT-Carer). Qual. Life Res. 24, 2601-2614 (2015). https://doi.org/10.1007/s11136-015-1011-x

19. Batchelder, L., Malley, J., Burge, P., Lu, H., Saloniki, E.-C., Linnosmaa, I., Trukeschitz, B., Forder, J.E.: Carer social care-related quality of life outcomes: estimating english preference weights for the adult social care outcomes toolkit for carers (ASCOT-Carer). Value Health 22, 1427-1440 (2019). https://doi.org/10.1016/j.jval. 2019.07.014

20. Coons, S.J., Rao, S., Keininger, D.L., Hays, R.D.: A comparative review of generic quality-of-life instruments. Pharmacoeconomics 17, 13-35 (2000). https://doi.org/10.2165/00019053-20001 7010-00002
21. Drummond, M.F., Sculpher, M.J., Claxton, K., Stoddart, G.L., Torrance, G.W.: Methods for the economic evaluation of health care programmes, 4th edn. Oxford University Press (2015)

22. Badia, X., Roset, M., Herdman, M., Kind, P.: A comparison of United Kingdom and Spanish general population time trade-off values for EQ-5D health states. Med. Decis. Making 21, 7-16 (2001). https://doi.org/10.1177/0272989x0102100102

23. Johnson, J.A., Luo, N., Shaw, J.W., Kind, P., Coons, S.J.: Valuations of EQ-5D health states: are the United States and United Kingdom different? Med. Care 43, 221-228 (2005). https://doi. org/10.1097/00005650-200503000-00004

24. Hunt, S.M., Alonso, J., Bucquet, D., Niero, M., Wiklund, I., McKenna, S.: Cross-cultural adaptation of health measures. Health Policy 19, 33-44 (1991). https://doi.org/10.1016/0168-8510(91) 90072-6

25. Guillemin, F., Bombardier, C., Beaton, D.: Cross-cultural adaptation of health-related quality of life measures: literature review and proposed guidelines. J. Clin. Epidemiol. 46, 1417-1432 (1993). https://doi.org/10.1016/0895-4356(93)90142-n

26. Kaplan, R.M., Feeny, D., Revicki, D.A.: Methods for assessing relative importance in preference based outcome measures. Qual. Life Res. 2, 467-475 (1993). https://doi.org/10.1007/bf00422221

27. Hajji, A., Trukeschitz, B., Malley, J., Batchelder, L., Saloniki, E., Linnosmaa, I., Lu, H.: Population-based preference weights for the adult social outcomes toolkit (ASCOT) for service users for Austria: findings from a best-worst experiment. Soc. Sci. Med. 250, 112792 (2020). https://doi.org/10.1016/j.socscimed.2020. 112792

28. Shiroiwa, T., Moriyama, Y., Nakamura-Thomas, H., Morikawa, M., Fukuda, T., Batchelder, L., Saloniki, E.-C., Malley, J.: Development of Japanese utility weights for the Adult Social Care Outcomes Toolkit (ASCOT) SCT4. Qual. Life Res. 29, 253-263 (2020). https://doi.org/10.1007/s11136-019-02287-6

29. Nguyen, L., Jokimäki, H., Linnosmaa, I., Saloniki, E.-C., Batchelder, L., Malley, J., Lu, H., Burge, P., Trukeschitz, B., Forder, J.: Do you prefer safety to social participation? Finnish populationbased preference weights for the adult social care outcomes toolkit (ASCOT) for service users. MDM Policy Practice (2021). https:// doi.org/10.1177/23814683211027902

30. Trukeschitz, B., Hajji, A., Batchelder, L., Saloniki, E., Linnosmaa, I., Malley, J.: What's important when caring for a loved one? Population-based preference weights for the adult social care outcomes toolkit for informal carers (ASCOT-Carer) for Austria. Qual. Life Res. (2021). https://doi.org/10.1007/ s11136-021-02775-8

31. Linnosmaa, I., Nguyen, L., Jokimäki, H.: The EXCELC project in Finland: the main descriptive findings from surveys using the adult social care outcomes toolkit (ASCOT). Discussion paper 29/2020 Finnish Institute for Health and Welfare (THL) (2020). https://www.julkari.fi/handle/10024/140416. Accessed 10 Jan 2021

32. Finn, A., Louviere, J.J.: Determining the appropriate response to evidence of public concern: the case of food safety. J. Pub. Policy Mark. 11, 12-25 (1992). https://doi.org/10.2165/00019053-20001 7010

33. Thurstone, L.L.: A law of comparative judgement. Psychol. Rev. 101, 266-270 (1994). https://doi.org/10.1037/0033-295X.101.2. 266

34. Carlsson, F., Mørkbak, M.R., Olsen, S.B.: The first time is the hardest: a test of ordering effects in choice experiments. J. Choice Model. 5, 19-37 (2012). https://doi.org/10.1016/S1755-5345(13) 70051-4

35. Day, B., Bateman, I.J., Carson, R.T., Dupont, D., Louviere, J.J., Morimoto, S., Scarpa, R., Wang, P.: Ordering effects and choice set awareness in repeat-response stated preference studies. J. 
Environ. Econ. Manag. 63, 73-91 (2012). https://doi.org/10. 1016/j.jeem.2011.09.001

36. Savage, S.J., Waldman, D.M.: Learning and fatigue during choice experiments: a comparison of online and mail survey modes. J. Appl. Econ. 23, 351-371 (2008). https://doi.org/10.1002/jae.984

37. Helter, T.M., Coast, J., Łaszewska, A., Stamm, T., Simon, J.: Capability instruments in economic evaluations of healthrelated interventions: a comparative review of the literature. Qual. Life Res. 29, 1433-1464 (2020). https://doi.org/10.1007/ s11136-019-02393-5

38. Flynn, T.N.: Valuing citizen and patient preferences in health: recent developments in three types of best-worst scaling. Expert Rev. Pharmacoecon. Outcomes Res. 10, 259-267 (2010). https:// doi.org/10.1586/erp.10.29

39. Potoglou, D., Burge, P., Flynn, T., Netten, A., Malley, J., Forder, J., Brazier, J.E.: Best-worst scaling vs discrete choice experiments: an empirical comparison using social care data. Soc. Sci. Med. 72, 1717-1727 (2011). https://doi.org/10.1016/j.socscimed. 2011.03.027

40. Louviere, J., Flynn, T., Marley, A.A.J.: Best-worst scaling: theory, methods and applications. Cambridge University Press (2015)

41. Hess, S., Train, K.: Correlation and scale in mixed logit models. J. Choice Model. 23, 1-8 (2017). https://doi.org/10.1016/j.jocm. 2017.03.001

42. Flynn, T.N., Huynh, E., Peters, T.J., Al-Janabi, H., Clemens, S., Moody, A., Coast, J.: Scoring the ICECAP-A capability instrument. Estimation of a UK general population tariff. Health Econ. 24, 258-269 (2015). https://doi.org/10.1002/hec.3014

43. Flynn, T.N., Marley, A.A.J.: Best-worst scaling: theory and methods. In: Hess, S., Daly, A. (eds.) Handbook of choice modelling, pp. 1-342. Edward Elgar Publishing Limited (2014)

44. Johnson, F.R., Lancsar, E., Marshall, D., Kilambi, V., Mühlbacher, A., Regier, D.A., Bresnahan, B.W., Kanninen, B., Bridges, J.F.: Constructing experimental designs for discrete-choice experiments: report of the ISPOR conjoint analysis experimental design good research practices task force. Value Health 16, 3-13 (2013). https://doi.org/10.1016/j.jval.2012.08.2223

45. Campbell, D., Boeri, M., Doherty, E., Hutchinson, W.G.: Learning, fatigue and preference formation in discrete choice experiments. J. Econ. Behav. Organ. 119, 345-363 (2015). https://doi. org/10.1016/j.jebo.2015.08.018

46. McFadden, D.: Conditional logit analysis of qualitative choice behavior. In: Zarembka, P. (ed.) Frontiers in econometrics, pp. 105-142. Academic Press (1974)

47. Louviere, J., Street, D., Carson, R., Ainslie, A., Deshazo, J.R., Cameron, T., Hensher, D., Kohn, R., Marley, T.: Dissecting the random component of utility. Mark. Lett. 13, 177-193 (2002). https://doi.org/10.1023/a:1020258402210

48. Fiebig, D.G., Keane, M.P., Louviere, J., Wasi, N.: The generalized multinomial logit model: accounting for scale and coefficient heterogeneity. Market. Sci. 29, 393-421 (2010). https://doi.org/ $10.1287 / \mathrm{mksc} .1090 .0508$

49. Bierlaire, M.: BIOGEME: a free package for the estimation of discrete choice models. Proceedings of the 3rd Swiss transportation research conference. Paper presented at the 3rd swiss transportation research conference, Ascona, Switzerland (2003). http://bioge me.epfl.ch. Accessed 9 Sept 2017

50. ALOGIT: ALOGIT Software \& Analysis Ltd. ALOGIT version 4.2. 2017. http://www.alogit.com/. Accessed 14 Sept 2017

51. Train, K.E.: Discrete choice methods with simulation. Second edition. Cambridge University Press (2009). https://eml.berkeley. edu/books/choice2.html. Accessed 31 July 2018

52. Hess, S., Hensher, D., Daly, A.J.: Not bored yet - revisiting respondent fatigue in stated choice experiments. Transp. Res. Part A Policy Pract. 46, 626-644 (2012). https://doi.org/10.1016/j.tra. 2011.11.008
53. DeBell, M., Krosnick, J.A.: Computing weights for American national election study survey data. ANES Technical Report Series, no. nes012427. American National Election Studies, Ann Arbor, MI, Palo Alto, CA (2009). https://electionstudies.org/wpcontent/uploads/2018/04/nes012427.pdf. Accessed 11 Feb 2021

54. Burge, P., Potoglou, D., Kim, C., Hess, S.: How do the public value different outcomes of social care? Estimation of preference weights for ASCOT. Santa Monica, CA: RAND Corporation, 2010. RAND Europe (2010). https://www.rand.org/pubs/worki ng_papers/WR744.html. Accessed 1 Mar 2018

55. Huynh, E., Coast, J., Rose, J., Kinghorn, P., Flynn, T.: Values for the ICECAP-supportive care measure (ICECAP-SCM) for use in economic evaluation at end of life. Soc. Sci. Med. 189, 114-128 (2017). https://doi.org/10.1016/j.socscimed.2017.07.012

56. Coast, J., Flynn, T.N., Natarajan, L., Sproston, K., Lewis, J., Louviere, J.J., Peters, T.J.: Valuing the ICECAP capability index for older people. Soc. Sci. Med. 67, 874-882 (2008). https://doi.org/ 10.1016/j.socscimed.2008.05.015

57. Hensher, D.A., Rose, J.M., Greene, W.H.: Applied choice analysis: a primer. Cambridge University Press (2005)

58. Campbell, D., Erdem, S.: Position bias in best-worst scaling surveys: a case study on trust in institutions. Am. J. Agri. Econ. 97, 526-545 (2015). https://doi.org/10.1093/ajae/aau112

59. Flynn, T.N., Louviere, J.J., Peters, T.J., Coast, J.: Using discrete choice experiments to understand preferences for quality of life Variance-scale Heterogeneity matters. Soc. Sci. Med. 70, 19571965 (2010). https://doi.org/10.1016/j.socscimed.2010.03.008

60. Salthouse, T.A., Kausler, D.H., Saults, J.S.: Age, self-assessed health status, and cognition. J. Gerontol. 45, P156-P160 (1990). https://doi.org/10.1093/geronj/45.4.p156

61. Mühlbacher, A.C., Kaczynski, A., Zweifel, P., Johnson, F.R.: Experimental measurement of preferences in health and healthcare using best-worst scaling: an overview. Health Econ. Rev. 6, 2-2 (2016). https://doi.org/10.1186/s13561-015-0079-x

62. Czajkowski, M., Giergiczny, M., Greene, W.H.: Learning and fatigue effects revisited: Investigating the effects of accounting for unobservable preference and scale heterogeneity. Land Econ. 90, 324-351 (2014). https://doi.org/10.3368/le.90.2.324

63. Saloniki, E.-C., Malley, J., Burge, P., Lu, H., Batchelder, L., Linnosmaa, I., Trukeschitz, B., Forder, J.: Comparing internet and face-to-face surveys as methods for eliciting preferences for social care-related quality of life: evidence from England using the ASCOT service user measure. Qual. Life Res. (2019). https:// doi.org/10.1007/s11136-019-02172-2

64. Makai, P., Brouwer, W.B., Koopmanschap, M.A., Stolk, E.A., Nieboer, A.P.: Quality of life instruments for economic evaluations in health and social care for older people: a systematic review. Soc. Sci. Med. 102, 83-93 (2014). https://doi.org/10.1016/j.socscimed. 2013.11.050

65. Bulamu, N.B., Kaambwa, B., Ratcliffe, J.: A systematic review of instruments for measuring outcomes in economic evaluation within aged care. Health Qual. Life Outcomes 13, 179 (2015). https://doi.org/10.1186/s12955-015-0372-8

66. Kjær, T., Bech, M., Gyrd-Hansen, D., Hart-Hansen, K.: Ordering effect and price sensitivity in discrete choice experiments: need we worry? Health Econ. 15, 1217-1228 (2006). https://doi.org/ 10.1002/hec. 1117

67. Murto, J., Kaikkonen, R., Pentala-Nikulainen, O., Koskela, T., Virtala, E., Härkänen, T., Koskenniemi, T., Jussmäki, T., Vartiainen, E., Koskinen, S.: Aikuisten terveys-, hyvinvointi- ja palvelututkimus ATH:n perustulokset 2010-2016. Finnish Institute for Health and Welfare THL, Helsinki (2018). Verkkojulkaisu: thl.fi/ ath. Accessed 21 Jan 2020

68. Statistics from Statistics Finland, Official Statistics of Finland (OSF), Helsinki: Dwellings and housing conditions 2015: 
dwellings and housing conditions [e-publication] (2015b). www. stat.fi/til/asas/tau_en.html. Accessed 23 Jan 2017

69. Educational structure of population 2015: Educational structure of population [e-publication]. Table: population aged 15 or over by level of education, municipality, gender, and age 1970-2015 (2015a). www.stat.fi/til/vkour/tau_en.html. Accessed 11 May 2018

70. Employment statistics 2016: Employment [e-publication]. Table: population by main type of activity, sex, yearly age groups and year 1987-2016 (2016b). www.stat.fi/til/tyokay/tau_en.html. Accessed 11 May 2018
71. Population Statistics 2016: Population structure [e-publication]. Table: population according to age (1-year), sex, marital status, and language by area 1990-2016 (2016a). www.tilastokeskus.fi/ til/vaerak/tau.html. Accessed 27 Apr 2017

72. Population Statistics 2016: Population structure [e-publication]. Table: Population by religious community, age, and sex in 2000 to 2016 (2016c). www.tilastokeskus.fi/til/vaerak/tau.html. Accessed 27 Apr 2017

Publisher's Note Springer Nature remains neutral with regard to jurisdictional claims in published maps and institutional affiliations. 